(2) Open Access Full Text Article

\title{
Association Analysis Between Catechol-O- Methyltransferase Expression and Cognitive Function in Patients with Schizophrenia, Bipolar Disorder, or Major Depression
}

This article was published in the following Dove Press journal:

Neuropsychiatric Disease and Treatment

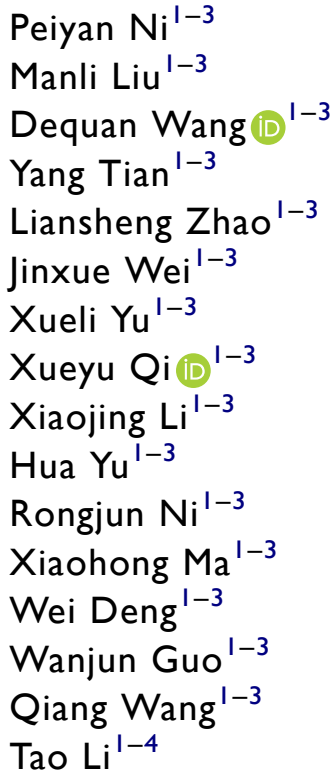

'The Psychiatric Laboratory, West China Hospital, Sichuan University, Chengdu, 6I004I, People's Republic of China; ${ }^{2}$ Mental Health Center, West China Hospital, Sichuan University, Chengdu, 6I004I, People's Republic of China; ${ }^{3}$ Huaxi Brain Research Center, West China Hospital, Sichuan University, Chengdu, 61004I, People's Republic of China; ${ }^{4}$ Guangdong-Hong Kong-Macao Greater Bay Area Center for Brain Science and Brain-Inspired Intelligence, Guangzhou, People's Republic of China

Correspondence: Tao $\mathrm{Li}$

The Psychiatric Laboratory, West China Hospital, Sichuan University, 28 Dian Xin Nan Road, Chengdu, Sichuan, 61004I,

People's Republic of China

Tel/Fax +86-28-8542356I

Email litaohx@scu.edu.cn
Introduction: Schizophrenia, bipolar disorder (BD), and major depressive disorder are three common mental disorders. Although their diagnosis and treatment differ, they partially overlap.

Methods: To explore the similarities and characteristics of these three psychiatric diseases, an intelligence quotient (IQ) assessment was performed to evaluate cognitive deficits. Relative catechol-O-methyltransferase (COMT) expression in peripheral blood mononuclear cells was examined in all three groups compared with healthy controls (HCs).

Results: The results indicated that patients with any of the three psychiatric diseases presented IQ deficits, and that the first-episode schizophrenia (FES) group had even lower cognitive function than the other two groups. The relative COMT expression decreased in the FES group and increased in the BD group compared with the HC group. The correlation analysis of COMT expression level and IQ scores showed a positive correlation between relative COMT expression and full-scale IQ in the HC group. However, this correlation disappeared in all three psychiatric diseases studied.

Conclusion: In conclusion, this cross-disease strategy provided important clues to explain lower IQ scores and dysregulated COMT expression among three common mental illnesses. Keywords: first-episode schizophrenia, FES, bipolar disorder, BD, first-episode major depressive disorder, MDD, catechol-O-methyltransferase, COMT, intelligence quotient, IQ

\section{Introduction}

Schizophrenia (SCZ), bipolar disorder (BD), and major depressive disorder (MDD) are three types of common mental diseases, which severely affect psychological, biological, and social functioning. Although their diagnosis and treatment are different, there is some overlap in symptoms and treatment. ${ }^{1-3}$ Although symptoms are complex and heterogeneous, cognitive impairment is prevalent in SCZ, BD, and MDD. ${ }^{4}$ Cognitive deficit is regarded as a core symptom of SCZ and BD. ${ }^{5,6}$ Cognitive impairment is also one of the most common symptoms of $\mathrm{MDD}^{7}$ and approximately $90 \%$ of patients with MDD complained about cognitive issues. ${ }^{8}$ The intelligence quotient (IQ) score refers to the intelligence level, which can rate the subjects' cognitive ability, is an important indicator of cognitive assessment. ${ }^{9}$ Numerous studies have shown that the aforementioned mental diseases can lead to an impaired IQ. ${ }^{10-12}$ Although higher childhood IQ may predict increased risk of 
adult mania, ${ }^{13}$ IQ impairments in childhood and adolescence are often observed in individuals who later develop $\mathrm{SCZ}, \mathrm{BD}$, and MDD. ${ }^{14}$

Mental disorders are multifactorial diseases influenced by both genetic and environmental factors. ${ }^{15-17}$ All three common mental disorders have a high heritability, ${ }^{18-20}$ which means that genes play a crucial role in the pathophysiology of these psychiatric diseases. Furthermore, diseaserelated susceptible genes/loci provide some clues for diagnosis and treatment. ${ }^{21-23}$ The catechol-O-methyltransferase (COMT) gene has been widely investigated because of its high correlation with the risk of common psychiatric diseases, especially SCZ. ${ }^{24-26}$ COMT is located on chromosome $22 \mathrm{q} 11.226^{27}$ and its single nucleotide polymorphisms (SNPs) are regarded as promising candidates for understanding the genetic basis of many common psychiatric disorders, especially rs4680, which can affect COMT activity. ${ }^{28}$ COMT transfers a methyl group from S-adenosylmethionine to catecholamines to degrade dopamine, epinephrine, and norepinephrine. ${ }^{28}$ Therefore, abnormal COMT expression or activity may cause dopaminergic dysfunction, which may, in turn, lead to common mental disease symptoms such as impaired cognition. ${ }^{29-31}$ A large number of studies focused on the relationship between the COMT gene and cognitive function in $\mathrm{SCZ}, \mathrm{BD}$, and $\mathrm{MDD},{ }^{32-35}$ while others have indicated that the relative risk of $\mathrm{SCZ}$ is 20 to 25 times higher in patients with 22q11.2 deletion syndrome (one COMT copy is deleted) than in the general population. ${ }^{36}$ Patients with a 22q11.2 deletion syndrome SCZ form also showed a lower IQ. ${ }^{37}$ In studies on BD, however, there are contradictory findings on the correlation between COMT and cognitive function. ${ }^{38}$ This inconsistency may be due to the fact that some studies did consider factors that may influence the cognitive performance of $\mathrm{BD}$ patients, such as disease stage or medical treatment at the time of assessment. ${ }^{39,40}$ Antypa et al proposed a tentative pathway whereby the COMT gene may influence cognitive vulnerability to depression. ${ }^{41}$ In healthy research participants, the COMT genotype could help predict a small proportion of the variance in baseline cognition and neurophysiology, ${ }^{42}$ but the association is modest and inconsistent. ${ }^{43}$ Therefore, it is very important to explore the correlation between COMT expression and IQ defects with cross-disease strategies among different mental illnesses.

Studies have suggested that both relative COMT expression and IQ assessment could dynamically change according to the state of the episode and pharmacologic treatment. ${ }^{30,39,40,44-46}$ To exclude the possible influence of pharmacologic treatment, the patients with SCZ and MDD included in this study were all drug-naïve first-episode subjects, and patients with BD did not take any medication 3 months before enrollment. In this cross-disease study, the combination of relative COMT expression and IQ assessment was considered to be a powerful approach to identify the potential path between the expression of risk genes and phenotype. We hypothesized that COMT expression was different in patients with mental disorders, and that the correlation between COMT expression and IQ scores may not be consistent.

\section{Methods}

\section{Demographic Characteristics and General Cognitive Function Assessment}

This study recruited 150 patients with FES (in acute or post-acute phase), 182 patients with BD (in depressive and manic as well as mixed phase), and 183 first-episode patients with MDD (in acute or post-acute phase) from the Mental Health Center of West China Hospital of Sichuan University. All patients were interviewed using the Structured Clinical Interview for Diagnostic and Statistical Manual of Mental Disorders, fourth edition (DSM-IV) Patient edition (SCID-P). Both patients with FES and MDD were drug-naïve, and patients with BD were not medicated in the 3 months prior to enrollment. All subjects were followed up for at least 6 months to further confirm the initial diagnosis. We also recruited 261 healthy controls (HCs) by poster advertisements within the local community in Chengdu, Sichuan Province, China. The HCs were interviewed using the SCID-NP. All subjects were recruited over the period from 2012-2016. IQ was tested using the short version of the Chinese Revised Wechsler Adult Intelligence Scale (WAIS-RC) according to the WAIS-RC manual. ${ }^{47}$ The IQ assessment included seven subtests: information, digital span, digital symbol, picture completion, block design, similarities, and arithmetic. Verbal IQ, performance IQ, and full-scale IQ were calculated referring to the weighted formulas previously described. ${ }^{47,48}$ This study was conducted in accordance with the Declaration of Helsinki. Approval for this study was granted by the Ethics Committee of the West China Hospital of Sichuan University. All participants signed an informed consent form, and patient's demographic characteristics are shown in Table 1. 


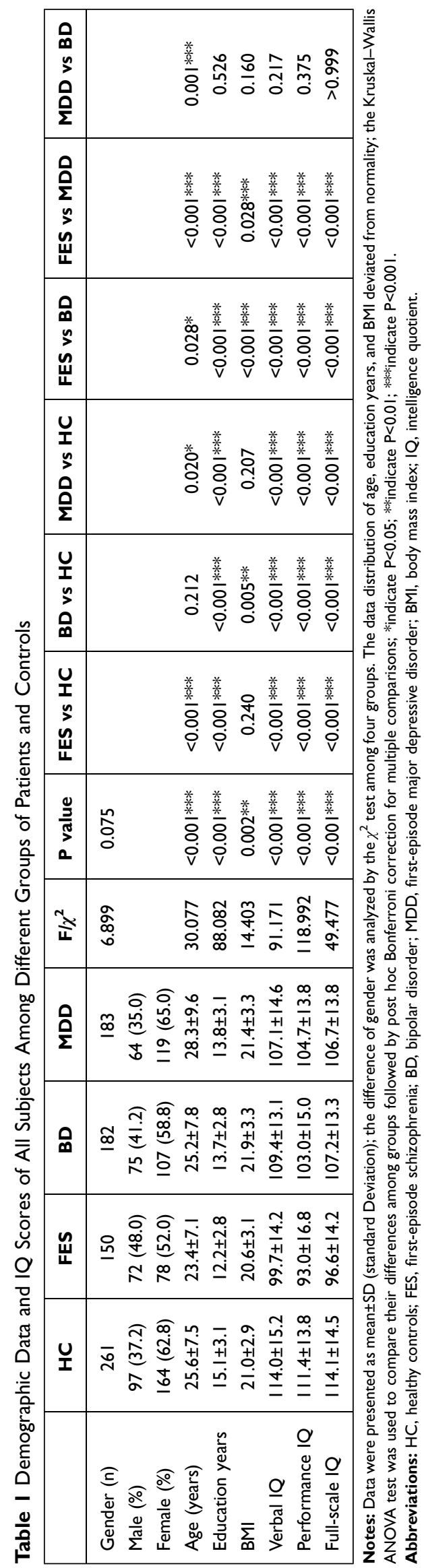

\section{Total RNA Extraction and Relative COMT} Expression

Patients not treated with any medication after cognitive function assessment were scheduled for peripheral blood mononuclear cell (PBMC) collection at 8:00-9:00AM. For the patients and healthy controls, whose demographic characteristics are shown in Table 2, and could attend the PBMC collection, peripheral blood samples $(3 \mathrm{~mL})$ were collected. For total RNA extraction, whole blood samples were immediately preserved in Tempus Blood RNA Tubes (Applied Biosystems, Foster, USA). To avoid blood coagulation, the tubes were vigorously mixed for $\geq 10$ seconds. All tubes were preserved at $-80^{\circ} \mathrm{C}$ until use. According to the manufacturer's instruction, total RNA was extracted from the sample with MagMAX for Stabilized Blood Tubes RNA Isolation Kit (Thermo Fisher Scientific, Waltham, USA). cDNA was generated using the iScript cDNA Synthesis Kit (Bio-Rad, Hercules, USA) with $1 \mu \mathrm{g}$ total RNA. Quantitative polymerase chain reaction (qPCR) was performed with the SsoFast EvaGreen $^{\text {TM }}$ Supermix Real-time PCR kit (Bio-Rad, Hercules, USA). Relative mRNA expression was measured using the CFX96TM Real-Time System (Bio-Rad, Hercules, USA). The PCR cycling parameters were: $95^{\circ} \mathrm{C}$ for 1 min for denaturing, followed by 40 cycles of a twostep PCR (melting for $10 \mathrm{~s}$ at $95^{\circ} \mathrm{C}$, annealing for $20 \mathrm{~s}$ at $60^{\circ} \mathrm{C}$ ). Relative COMT mRNA expression was analyzed using the $2^{-\Delta \Delta \mathrm{Ct}}$ method and normalized by GAPDH expression. The corresponding primer sequences are listed as follows:

COMT, Sense Primer: 5'-CGACTGTGCCGCCATCA Anti-sense Primer: 5'-GCAGCAGGCCACATTCCTC GAPDH, Sense Primer: 5'-GTCTCCTCTGACTTCA ACAGCG

Anti-sense Primer: 5'-ACCACCCTGTTGCTGTA GCCAA.

\section{Statistical Analyses}

All statistical analyses were performed using SPSS version 24 (IBM, Armonk, USA). The chi-square $\left(\chi^{2}\right)$ test was conducted to compare the frequency difference in qualitative characteristics (ie, gender) among the four groups. The Shapiro-Wilk test was employed for the normal distribution test, and equal variance was tested by Levene's test. Statistical analysis was performed using Welch's ANOVA test followed by the post hoc Tamhane's T2 test when normal distribution was 


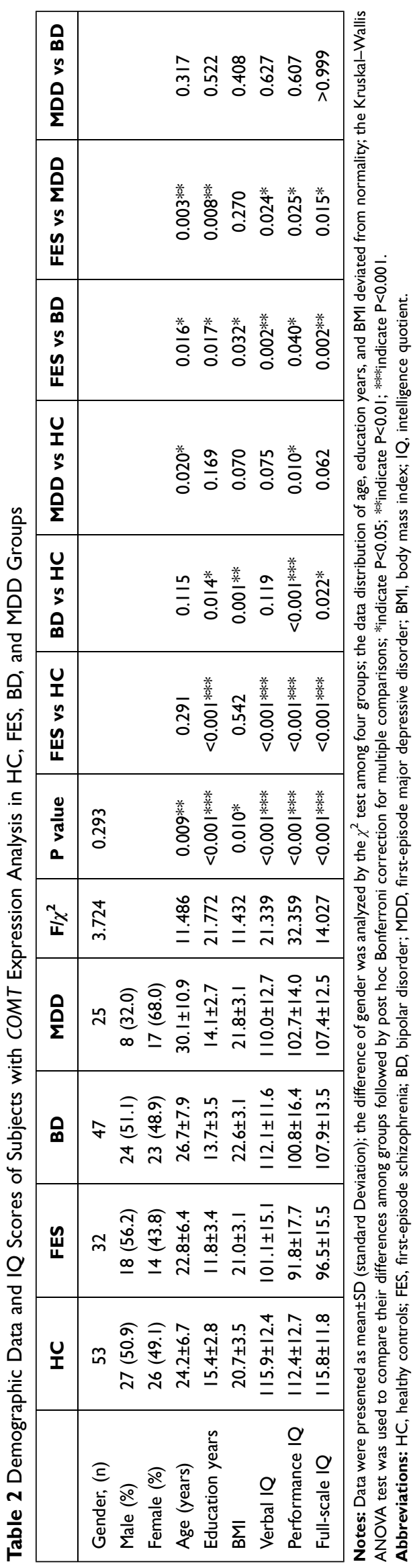

assumed, but equal variance was not. When the data distribution deviated from normality, the KruskalWallis ANOVA test was used to compare differences among groups followed by post hoc Bonferroni correction for multiple comparisons. The statistical methods for each statistical result are detailed in Supplementary Tables 1 and 2 . Correlation between IQ and relative COMT expression in each group was examined by a partial correlation analysis with age, education years, and BMI as covariates.

\section{Results \\ Demographic Characteristics}

The demographic data of all subjects are shown in Table 1. A total of 776 subjects participated in this study, including $261 \mathrm{HC}(97 \mathrm{M} / 164 \mathrm{~F}), 150 \mathrm{FES}(72 \mathrm{M} /$ 78F), $182 \mathrm{BD}(75 \mathrm{M} / 107 \mathrm{~F})$, and $183 \mathrm{MDD}(64 \mathrm{M} / 119 \mathrm{~F})$. There was no significant difference in gender among groups $\left(\chi^{2}=6.899, \mathrm{p}=0.075\right)$. However, age $\left(\chi^{2}=30.077\right.$, $\mathrm{p}<0.001)$, education years $\left(\chi^{2}=88.082, \mathrm{p}<0.001\right)$, and BMI $\left(\chi^{2}=14.403, p=0.002\right)$ were significantly different among groups. Patients with FES had the lowest average age at onset and education years, which was significantly lower than that of the HC group (age: $p<0.001$; education years: $p<0.001$ ) and patients with $\mathrm{BD}$ (age: $\mathrm{p}<0.001$; education years: $\mathrm{p}<0.001$ ) or MDD (age: $\mathrm{p}=0.028$; education years: $p<0.001$ ). With respect to BMI, patients with $\mathrm{BD}$ had a significantly higher BMI than $\mathrm{HC}(\mathrm{p}=0.005)$ and FES $(\mathrm{p}<0.001)$.

\section{Lower IQ Scores of Patients with Psychiatric Disease}

As shown in Table 1, there were significant differences in verbal IQ score $\left(\chi^{2}=91.171, \mathrm{p}<0.001\right)$, performance IQ score $\left(\chi^{2}=118.992, \mathrm{p}<0.001\right)$, and full-scale IQ score $\left(\mathrm{F}_{(3,772)}=49.477, \mathrm{p}<0.001\right)$ among the four groups. Compared with the $\mathrm{HC}$ group, all psychiatric groups showed lower verbal IQ, performance IQ, and full-scale IQ. Among psychiatric groups, all IQ scores of the FES group were significantly lower than those of the BD group (verbal IQ score: $\mathrm{p}<0.001$, performance IQ score: $\mathrm{p}<0.001$, and full-scale IQ score: $\mathrm{p}<0.001$ ) and MDD group (verbal IQ score: $\mathrm{p}<0.001$, performance IQ score: $\mathrm{p}<0.001$, and full-scale IQ score: $\mathrm{p}<0.001$ ). However, no difference in any IQ scores was found between the BD and MDD groups. 


\section{Dysregulated COMT Expression in}

\section{Patients with Psychiatric Disease}

Consistent with the overall demographic data, the subjects with analyzed COMT expression well represented the demographic distribution of all subjects (Table 2). Meanwhile, the IQ score distribution in the subgroup with analyzed COMT expression was also very similar to the overall results of all subjects (Table 2). There were significant differences in relative $C O M T$ expression among all groups $\left(\mathrm{F}_{(3,153)}=40.120, \mathrm{p}<0.001\right)$. Compared with the HC group, there was a significantly lower COMT expression in the FES group $(\mathrm{p}<0.001)$ while COMT expression was upregulated in the BD group $(\mathrm{p}=0.001)$, and no difference was observed in the MDD group $(p=0.248)$ (Figure 1A). The partial correlation analysis results of IQ scores and relative COMT expression in all groups are listed in Table 3. As shown in Figure 1B, the full-scale IQ score was positively correlated with relative COMT expression in the HC group ( $\mathrm{r}=0.301, \mathrm{p}=0.040)$.

\section{Discussion}

There is certain overlap in symptoms and treatment among the three common mental diseases examined here: SCZ, $\mathrm{BD}$, and MDD. It is therefore of great significance for the objective diagnosis and precise treatment of these mental diseases to explore their similarities and characteristics. In this study, we identified consistent IQ impairment and different COMT expression in PBMCs among patients with FES, BD, and MDD, suggesting that a cross-disease strategy could provide important clues for the phenotypic and mechanistic characterization of mental diseases.

As an effective indicator of state assessment, IQ scores were used to evaluate the cognitive function of patients with different psychiatric diseases. ${ }^{9-12}$ In this study, we found that the IQ scores of all three groups of patients with psychiatric diseases were significantly decreased, especially in the FES group, consistent with the severe cognitive impairment of FES patients observed in clinical practice. ${ }^{49,50}$ Worse cognitive impairment and earlier age at onset ${ }^{51-53}$ are possible explanations for the younger age and fewer education years of FES patients in this study.

Interestingly, the relative COMT expression in FES and $\mathrm{BD}$ groups presented an opposite trend compared with the $\mathrm{HC}$ group, that is, COMT expression significantly decreased in the FES group and increased in the BP group. According to previous studies, COMT is a risk gene for $\mathrm{SCZ}, \mathrm{BD}$, and MDD, and its risk effects are not consistent in different mental illnesses. $^{54,55}$ The inconsistent relative COMT expression in
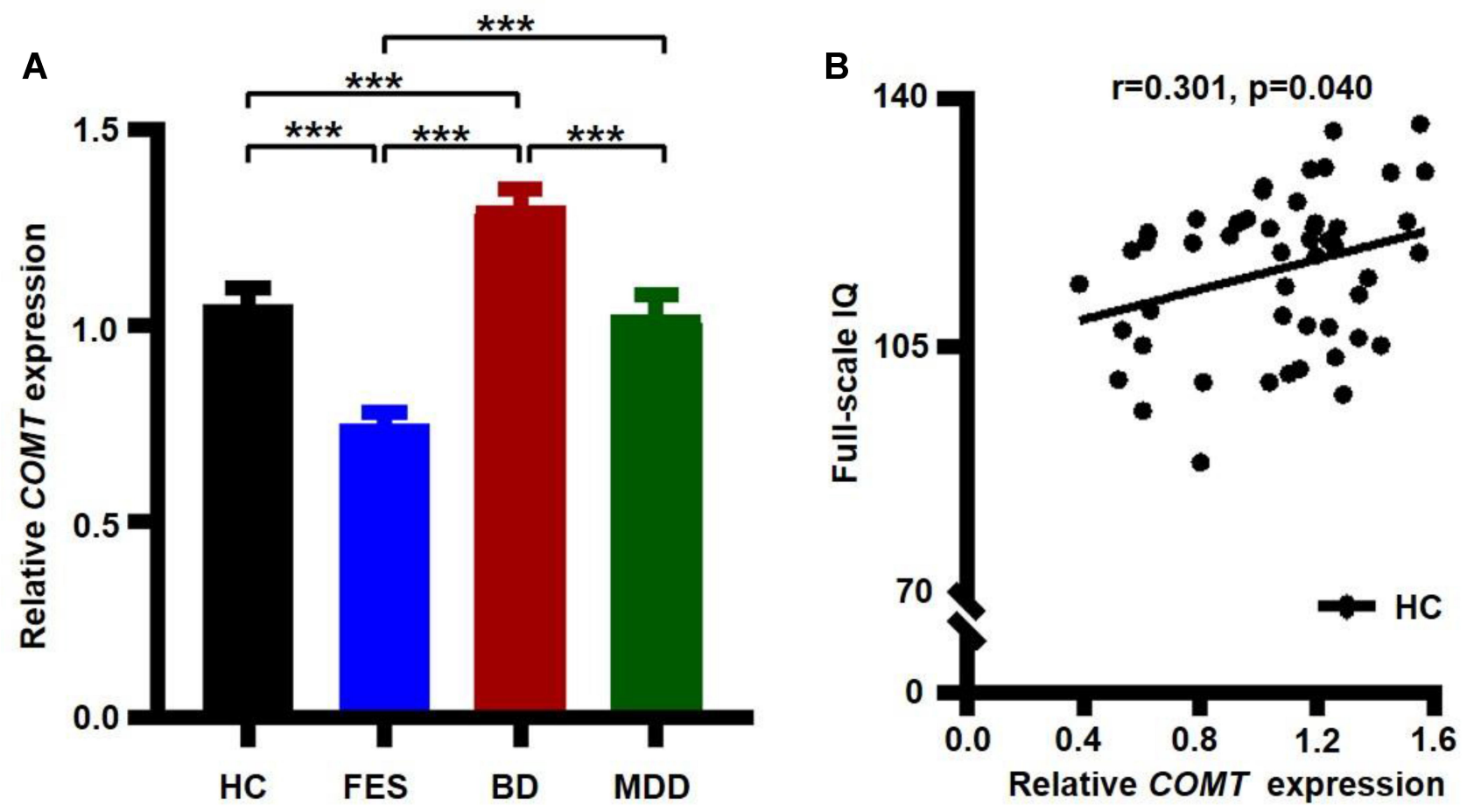

Figure I Full-scale IQ score positively correlated with relative COMT expression in the HC group. (A) Relative COMT expression among different groups of patients and controls. (B) Correlation analysis of COMT expression and full-scale IQ score in the HC group. Gene expression data normalized by GAPDH expression. Data are presented as mean \pm SEM. Asterisks indicate $\mathrm{P}<0.001$. 
Table 3 The Correlation of Verbal IQ, Performance IQ, Full Scale IQ with Relative COMT Expression in All Groups

\begin{tabular}{|l|c|c|c|c|c|c|c|c|}
\hline \multirow{2}{*}{ IQ } & \multicolumn{2}{|c|}{ HC } & \multicolumn{2}{c|}{ FES } & \multicolumn{2}{c|}{ BD } & \multicolumn{2}{c|}{ MDD } \\
\cline { 2 - 9 } & $\mathbf{r}$ & $\mathbf{P}$ & $\mathbf{r}$ & $\mathbf{P}$ & $\mathbf{r}$ & $\mathbf{P}$ & $\mathbf{r}$ \\
\hline Verbal IQ & 0.285 & 0.052 & -0.129 & 0.539 & 0.031 & 0.843 & -0.164 & 0.466 \\
Performance IQ & 0.199 & 0.179 & 0.078 & 0.711 & -0.080 & 0.605 & -0.066 & 0.769 \\
Full scale IQ & 0.301 & $0.040^{*}$ & -0.035 & 0.867 & -0.027 & 0.861 & -0.124 & 0.582 \\
\hline
\end{tabular}

Notes: Data were analyzed by Partial correlation analysis after adjusting for age, education years and BMI; *indicate $\mathrm{P}<0.05$.

Abbreviations: HC, healthy controls; FES, first-episode schizophrenia; BD, bipolar disorder; MDD, first-episode major depressive disorder; IQ, intelligence quotient.

PBMCs among patients with SCZ and BD in this study might be due to genetic risk, ${ }^{56}$ the disease course, ${ }^{57,58}$ or the sample size, which may also be another important factor. ${ }^{30,58}$ COMT is known to play an important role in the biological process of dopamine degradation through methyl transfer. ${ }^{28}$ The relationship between dopamine levels and cognitive function presents an inverted U-shaped pattern, ${ }^{59}$ thus implying the existence of an optimal dopamine level, and those with lower and higher predicted dopamine levels perform worse, ${ }^{60}$ which has fundamental implications for the effects of dopaminergic treatment on cognition, ${ }^{61}$ and also suggests that the expression level of COMT has meaningful implications for cognitive impairment and its potential biological mechanisms. To explore this significance, a correlation analysis of COMT expression level and IQ score was performed. The results showed that there was a positive correlation between relative COMT expression and full-scale IQ only in the HC group. This correlation disappeared in all groups with psychiatric diseases. As mentioned above, the U-shaped pattern between dopamine concentration and cognitive function ${ }^{59}$ might mean that abnormal COMT expression may lead to its negative correlation with lower IQ in the three groups with psychiatric diseases.

Some limitations of the current study should be mentioned. The present observations await replication with a larger sample size in future studies, and more cognitive domains such as executive functions and working memory should be considered. Although PBMCs are more accessible, considering the tissue/cell specificity of COMT expression, research based on postmortem samples and/or specific neurons differentiated from induced pluripotent stem cells (iPSCs) will provide a more deliberate opportunity to explore the biological mechanism. Even though all patients in the FES and MDD groups were drug-naïve first-episode, the patients with BD may have taken some medications that affect COMT expression or cognitive responses during previous episodes of mania or depression, such as dopamine agonists. ${ }^{62}$ Considering that such treatment can change the relative COMT expression, ${ }^{30}$ it is difficult to rule out whether the abnormal COMT expression observed in the BD group corresponded to diseaseinnate abnormalities or was a side-effect of drug treatment. As a cross-sectional study, this study did not examine the effects of drug treatments on relative COMT expression. Therefore, subsequent longitudinal studies might provide evidence to support relative COMT expression as a biological marker for psychiatric diseases.

\section{Acknowledgment}

This study was supported by the National Natural Science Foundation of China (81871054, 81501159, 81630030 and 81920108018); Key-Area Research and Development Program of Guangdong Province (2018B030334001); the Department of Science and Technology of Sichuan provincial government (2019YFS0153); and the 1.3.5 Project for disciplines of excellence, West China Hospital of Sichuan University (T.L., ZY2016103, ZY2016203, and ZYGD20004).

\section{Author Contributions}

All authors made substantial contributions to conception and design, acquisition of data, or analysis and interpretation of data; took part in drafting the article or revising it critically for important intellectual content; agreed to submit to the current journal; gave final approval of the version to be published; and agree to be accountable for all aspects of the work.

\section{Disclosure}

The authors have no potential conflicts of interest to disclose.

\section{References}

1. St Clair D, Blackwood D, Muir W, et al. Association within a family of a balanced autosomal translocation with major mental illness. Lancet. 1990;336(8706):13-16. doi:10.1016/0140-6736(90)91520-K 
2. Craddock N, O'Donovan MC, Owen MJ. The genetics of schizophrenia and bipolar disorder: dissecting psychosis. J Med Genet. 2005;42(3):193-204. doi:10.1136/jmg.2005.030718

3. Wood MD, Wren PB. Serotonin-dopamine interactions: implications for the design of novel therapeutic agents for psychiatric disorders. Prog Brain Res. 2008;172:213-230.

4. Ferrer A, Labad J, Salvat-Pujol N, et al. Hypothalamic-pituitaryadrenal axis-related genes and cognition in major mood disorders and schizophrenia: a systematic review. Prog Neuropsycho pharmacol Biol Psychiatry. 2020;101:109929. doi:10.1016/j. pnpbp.2020.109929

5. Elvevag B, Goldberg TE. Cognitive impairment in schizophrenia is the core of the disorder. Crit Rev Neurobiol. 2000;14(1):1-21. doi:10.1615/CritRevNeurobiol.v14.i1.10

6. Sheffield JM, Karcher NR, Barch DM. Cognitive deficits in psychotic disorders: a lifespan perspective. Neuropsychol Rev. 2018;28 (4):509-533.

7. Rock PL, Roiser JP, Riedel WJ, Blackwell AD. Cognitive impairment in depression: a systematic review and meta-analysis. Psychol Med. 2014;44(10):2029-2040. doi:10.1017/S0033291713002535

8. Conradi HJ, Ormel J, de Jonge P. Presence of individual (residual) symptoms during depressive episodes and periods of remission: a 3year prospective study. Psychol Med. 2011;41(6):1165-1174. doi:10.1017/S0033291710001911

9. Deary IJ. Intelligence. Annu Rev Psychol. 2012;63:453-482. doi:10.1146/annurev-psych-120710-100353

10. Van Haren NEM, Van Dam DS, Stellato RK, Genetic R. Outcome of Psychosis i. Change in IQ in schizophrenia patients and their siblings: a controlled longitudinal study. Psychol Med. 2019;49(15):25732581. doi:10.1017/S0033291718003537

11. Keyes KM, Platt J, Kaufman AS, McLaughlin KA. Association of fluid intelligence and psychiatric disorders in a population-representative sample of US adolescents. JAMA Psychiatry. 2017;74(2):179188. doi:10.1001/jamapsychiatry.2016.3723

12. Zhang Y, Li M, Wang Q, et al. A joint study of whole exome sequencing and structural MRI analysis in major depressive disorder. Psychol Med. 2020;50(3):384-395. doi:10.1017/S003329171 9000072

13. Koenen KC, Moffitt TE, Roberts AL, et al. Childhood IQ and adult mental disorders: a test of the cognitive reserve hypothesis. $\mathrm{Am} \mathrm{J}$ Psychiatry. 2009;166(1):50-57. doi:10.1176/appi.ajp.2008.08030343

14. Zammit S, Allebeck P, David AS, et al. A longitudinal study of premorbid IQ Score and risk of developing schizophrenia, bipolar disorder, severe depression, and other nonaffective psychoses. Arch Gen Psychiatry. 2004;61(4):354-360. doi:10.1001/archpsyc.61.4.354

15. Owen MJ, Sawa A, Mortensen PB. Schizophrenia. Lancet. 2016;388 (10039):86-97. doi:10.1016/S0140-6736(15)01121-6

16. Aldinger F, Schulze TG. Environmental factors, life events, and trauma in the course of bipolar disorder. Psychiatry Clin Neurosci. 2017;71(1):6-17. doi:10.1111/pcn.12433

17. Fabbri C. Genetic and environmental contribution to major depressive disorder and self-declared depression. EBioMedicine. 2016;14:7-8. doi:10.1016/j.ebiom.2016.11.030

18. Sullivan PF, Neale MC, Kendler KS. Genetic epidemiology of major depression: review and meta-analysis. Am J Psychiatry. 2000;157 (10):1552-1562. doi:10.1176/appi.ajp.157.10.1552

19. Barnett JH, Smoller JW. The genetics of bipolar disorder. Neuroscience. 2009;164(1):331-343. doi:10.1016/j. neuroscience.2009.03.080

20. Hilker R, Helenius D, Fagerlund B, et al. Heritability of schizophrenia and schizophrenia spectrum based on the nationwide danish twin register. Biol Psychiatry. 2018;83(6):492-498. doi:10.1016/j. biopsych.2017.08.017

21. Schizophrenia Working Group of the Psychiatric Genomics C. Biological insights from 108 schizophrenia-associated genetic loci. Nature. 2014;511(7510):421-427. doi:10.1038/nature13595
22. Wray NR, Ripke S, Mattheisen M, et al. Genome-wide association analyses identify 44 risk variants and refine the genetic architecture of major depression. Nat Genet. 2018;50(5):668-681. doi:10.1038/ s41588-018-0090-3

23. Coleman JRI, Gaspar HA, Bryois J, et al. The genetics of the mood disorder spectrum: genome-wide association analyses of more than 185,000 cases and 439,000 controls. Biol Psychiatry. 2020;88:169-184.

24. Shifman S, Bronstein M, Sternfeld M, et al. A highly significant association between a COMT haplotype and schizophrenia. Am J Hum Genet. 2002;71(6):1296-1302. doi:10.1086/344514

25. Burdick KE, Funke B, Goldberg JF, et al. COMT genotype increases risk for bipolar I disorder and influences neurocognitive performance. Bipolar Disord. 2007;9(4):370-376. doi:10.1111/j.1399-5618.2007.00384.x

26. Baune BT, Hohoff C, Berger K, et al. Association of the COMT val158met variant with antidepressant treatment response in major depression. Neuropsychopharmacology. 2008;33(4):924-932. doi:10.1038/sj.npp.1301462

27. Grossman MH, Emanuel BS, Budarf ML. Chromosomal mapping of the human catechol-O-methyltransferase gene to 22q11.1- $\mathrm{q} 11.2$. Genomics. 1992;12(4):822-825. doi:10.1016/0888-7543(92)90316-K

28. Lachman HM, Papolos DF, Saito T, Yu YM, Szumlanski CL, Weinshilboum RM. Human catechol-O-methyltransferase pharmacogenetics: description of a functional polymorphism and its potential application to neuropsychiatric disorders. Pharmacogenetics. 1996;6 (3):243-250. doi:10.1097/00008571-199606000-00007

29. Tunbridge E, Burnet PW, Sodhi MS, Harrison PJ. Catechol-o-methyltransferase (COMT) and proline dehydrogenase (PRODH) mRNAs in the dorsolateral prefrontal cortex in schizophrenia, bipolar disorder, and major depression. Synapse. 2004;51(2):112-118. doi:10.1002/syn.10286

30. Noto C, Ota VK, Santoro ML, et al. Depression, cytokine, and cytokine by treatment interactions modulate gene expression in antipsychotic naive first episode psychosis. Mol Neurobiol. 2016;53 (8):5701-5709. doi:10.1007/s12035-015-9489-3

31. Nohesara S, Ghadirivasfi M, Mostafavi S, et al. DNA hypomethylation of MB-COMT promoter in the DNA derived from saliva in schizophrenia and bipolar disorder. $J$ Psychiatr Res. 2011;45 (11):1432-1438. doi:10.1016/j.jpsychires.2011.06.013

32. Taylor S. Association between COMT Val158Met and psychiatric disorders: a comprehensive meta-analysis. Am J Med Genet Part B. 2018;177(2):199-210. doi:10.1002/ajmg.b.32556

33. Scheggia D, Sannino S, Scattoni ML, Papaleo F. COMT as a drug target for cognitive functions and dysfunctions. CNS Neurol Disord Drug Targets. 2012;11(3):209-221. doi:10.2174/187152712800672481

34. Savitz J, Solms M, Ramesar R. The molecular genetics of cognition: dopamine, COMT and BDNF. Genes Brain Behav. 2006;5(4):311328. doi:10.1111/j.1601-183X.2005.00163.x

35. Diaz-Asper CM, Weinberger DR, Goldberg TE. Catechol-O-methyltransferase polymorphisms and some implications for cognitive therapeutics. NeuroRx. 2006;3(1):97-105. doi:10.1016/j.nurx.2005.12.010

36. Bassett AS, Chow EW, Weksberg R. Chromosomal abnormalities and schizophrenia. Am J Med Genet. 2000;97(1):45-51. doi:10.1002/ (SICI)1096-8628(200021)97:1<45::AID-AJMG6>3.0.CO;2-9

37. Bassett AS, Chow EW. Schizophrenia and 22q11.2 deletion syndrome. Curr Psychiatry Rep. 2008;10(2):148-157. doi:10.1007/ s11920-008-0026-1

38. Pigoni A, Lazzaretti M, Mandolini GM, et al. The impact of COMT polymorphisms on cognition in bipolar disorder: a review: special section on "translational and neuroscience studies in affective disorders" section Editor, Maria Nobile MD, PhD. This Section of JAD focuses on the relevance of translational and neuroscience studies in providing a better understanding of the neural basis of affective disorders. The main aim is to briefly summaries relevant research findings in clinical neuroscience with particular regards to specific innovative topics in mood and anxiety disorders. $J$ Affect Disord. 2019;243:545-551. doi:10.1016/j. jad.2018.08.009 
39. Flowers SA, Ryan KA, Lai Z, McInnis MG, Ellingrod VL. Interaction between COMT rs5993883 and second generation antipsychotics is linked to decreases in verbal cognition and cognitive control in bipolar disorder. BMC Psychol. 2016;4:14. doi:10.1186/ s40359-016-0118-3

40. Hukic DS, Frisen L, Backlund L, et al. Cognitive manic symptoms in bipolar disorder associated with polymorphisms in the DAOA and COMT genes. PLoS One. 2013;8(7):e67450. doi:10.1371/journal. pone.0067450

41. Antypa N, Drago A, Serretti A. The role of COMT gene variants in depression: bridging neuropsychological, behavioral and clinical phenotypes. Neurosci Biobehav Rev. 2013;37(8):1597-1610. doi:10.1016/j.neubiorev.2013.06.006

42. Egan MF, Goldberg TE, Kolachana BS, et al. Effect of COMT Val108/158 Met genotype on frontal lobe function and risk for schizophrenia. Proc Natl Acad Sci U S A. 2001;98(12):6917-6922. doi:10.1073/pnas.111134598

43. Dickinson D, Elvevag B. Genes, cognition and brain through a COMT lens. Neuroscience. 2009;164(1):72-87. doi:10.1016/j. neuroscience.2009.05.014

44. Chamorro L, de Felipe MV, Soler MM, Olivares D, Huertas D. Intellectual capacity measurement in schizophrenia. Actas Esp Psiquiatr. 2008;36(1):33-38.

45. Vreeker A, Abramovic L, Boks MPM, et al. The relationship between brain volumes and intelligence in bipolar disorder. J Affect Disord. 2017;223:59-64. doi:10.1016/j.jad.2017.07.009

46. Molero P, Ortuno F, Zalacain M, Patino-Garcia A. Clinical involvement of catechol-O-methyltransferase polymorphisms in schizophrenia spectrum disorders: influence on the severity of psychotic symptoms and on the response to neuroleptic treatment. Pharmacogenomics J. 2007;7(6):418-426. doi:10.1038/sj. tpj.6500441

47. Wechsler D. WAIS-R: Manual:Wechsler Adult Intelligence ScaleRevised. San Antonio, TX: The Psychological Corporation; 1981.

48. Schopp LH, Callahan CD, Johnstone B, Schwake CJ. Utility of a seven-subtest version of the WAIS-R among an Alzheimer's disease sample. Arch Clin Neuropsychol. 1998;13(7):637-643.

49. Vohringer PA, Barroilhet SA, Amerio A, et al. Cognitive impairment in bipolar disorder and schizophrenia: a systematic review. Front Psychiatry. 2013;4:87. doi:10.3389/fpsyt.2013.00087

50. Keefe RS. Should cognitive impairment be included in the diagnostic criteria for schizophrenia? World Psychiatry. 2008;7(1):22-28. doi:10.1002/j.2051-5545.2008.tb00142.x

51. Javitt DC, Sweet RA. Auditory dysfunction in schizophrenia: integrating clinical and basic features. Nat Rev Neurosci. 2015;16 (9):535-550. doi:10.1038/nrn4002
52. Lin CY, Chang KW, Lin CY, et al. Allele-specific expression in a family quartet with autism reveals mono-to-biallelic switch and novel transcriptional processes of autism susceptibility genes. Sci Rep. 2018;8(1):4277. doi:10.1038/s41598-018-22753-4

53. Burke KC, Burke JD, Rae DS, Regier DA. Comparing age at onset of major depression and other psychiatric disorders by birth cohorts in five US community populations. Arch Gen Psychiatry. 1991;48 (9):789-795. doi:10.1001/archpsyc.1991.01810330013002

54. Dempster EL, Mill J, Craig IW, Collier DA. The quantification of COMT mRNA in post mortem cerebellum tissue: diagnosis, genotype, methylation and expression. BMC Med Genet. 2006;7:10. doi:10.1186/1471-2350-7-10

55. Silberschmidt AL, Sponheim SR. Personality in relation to genetic liability for schizophrenia and bipolar disorder: differential associations with the COMT Val 108/158 Met polymorphism. Schizophr Res. 2008;100(1-3):316-324. doi:10.1016/j.schres.2007.12.467

56. Tunbridge EM, Weinberger DR, Harrison PJ. A novel protein isoform of catechol O-methyltransferase (COMT): brain expression analysis in schizophrenia and bipolar disorder and effect of Val158Met genotype. Mol Psychiatry. 2006;11(2):116-117. doi:10.1038/sj. mp.4001767

57. Matsumoto M, Weickert CS, Beltaifa S, et al. Catechol O-methyltransferase (COMT) mRNA expression in the dorsolateral prefrontal cortex of patients with schizophrenia. Neuropsychopharmacology. 2003;28(8):1521-1530. doi:10.1038/sj.npp.1300218

58. Li Z, He Y, Han H, et al. COMT, 5-HTR2A, and SLC6A4 mRNA expressions in first-episode antipsychotic-naive schizophrenia and association with treatment outcomes. Front Psychiatry. 2018;9:577. doi:10.3389/fpsyt.2018.00577

59. Jenkins PO, Mehta MA, Sharp DJ. Catecholamines and cognition after traumatic brain injury. Brain. 2016;139(Pt 9):2345-2371. doi:10.1093/brain/aww128

60. Fallon SJ, Smulders K, Esselink RA, van de Warrenburg BP, Bloem BR, Cools R. Differential optimal dopamine levels for set-shifting and working memory in Parkinson's disease. Neuropsychologia. 2015;77:42-51. doi:10.1016/j.neuropsychologia.2015.07.031

61. Zahrt J, Taylor JR, Mathew RG, Arnsten AF. Supranormal stimulation of D1 dopamine receptors in the rodent prefrontal cortex impairs spatial working memory performance. $J$ Neurosci. 1997;17 (21):8528-8535. doi:10.1523/JNEUROSCI.17-21-08528.1997

62. Cools R, Frank MJ, Gibbs SE, Miyakawa A, Jagust W, D’Esposito M. Striatal dopamine predicts outcome-specific reversal learning and its sensitivity to dopaminergic drug administration. J Neurosci. 2009;29(5):1538-1543. doi:10.1523/JNEUROSCI.4467-08.2009
Neuropsychiatric Disease and Treatment

\section{Publish your work in this journal}

Neuropsychiatric Disease and Treatment is an international, peerreviewed journal of clinical therapeutics and pharmacology focusing on concise rapid reporting of clinical or pre-clinical studies on a range of neuropsychiatric and neurological disorders. This journal is indexed on PubMed Central, the 'PsycINFO' database and CAS, and is the official journal of The International Neuropsychiatric Association (INA). The manuscript management system is completely online and includes a very quick and fair peer-review system, which is all easy to use. Visit http://www.dovepress.com/testimonials.php to read real quotes from published authors. 